\title{
ECONOMICS, POLITICS AND EDUCATION: KENYA'S HARAMBEE INSTITUTES OF TECHNOLOGY
}

\author{
Martin Godfrey and G.C.M. Mutiso*
}

'Harambee!', meaning 'Pull Together!', is Kenya's national motto. Over the years it has become used to describe projects for which resources are raised by self-help methods, independently of government. Local committees have initiated harambee health centres, cattle dips, dams, roads, community buildings, schools, fish ponds, bridges and youth centres. Perhaps the best known internationally of Kenya's harambee projects since independence have been the harambee secondary schools which could be described as the major force behind the explosive expansion of the country's secondary education system during the 1960s. In 1971 the harambee movement took an interesting and unexpected new turn, when local self-help committees throughout Kenya began raising large sums of money for the establishment of harambee institutes of technology. The idea caught the national imagination in an unprecedented way and by October 1973 such institutes had been proposed for fourteen districts, in addition to two already in operation. This article is a short report on research carried out by the authors in 1972/73 under the auspices of IDS Nairobi, into the origins and prospects of these embryo institutions. ${ }^{1}$

The sponsors of the institutes of technology have made educational history. Technical training in Africa has usually been foisted on unwilling recipients by paternalistic colonial governments, missionaries or foreign advisers. In this case, by contrast, it has been wholly initiated by local interests. As King ${ }^{2}$ says, Kenya is the 'first country voluntarily

* Martin Godfrey is a Fellow at the Institute of Development Studies. G.C.M. Mutiso is a Senior Lecturer in Government, University of Nairobi.

1 Fuller reports are contained in: The Political Economy of Self-Help: Kenya's 'Harambee' Institutes of Technology, Canadian Journal of African Studies, vol. VIII no. 1, 1974, and Politics, Economics and Technical Training - a Kenyan case study, East African Literature Bureau, forthcoming.

2 Kenneth King, 'Some Preliminary Notes on 'Technological Self-Help in Kenya', paper in Developmental Trends in Kenya, proceedings of a seminar held in the Centre of African Studies, University of Edinburgh, April 1972. 
to espouse training on this scale in Africa'. For an explanation of these surprising institutions we have to look to a conjunction of political and economic trends.

During the first ten years of independence, in the absence of a strong political party with a systematic ideology, support from constituencies needed to be won through proofs of effectiveness in promoting local development. Politics moved from the capital to the outlying districts and became increasingly tribal. Meanwhile, within the African class which came to power after independence, the civil servants were beginning to establish their supremacy over the professional politicians. The salary-structure, related to educational level and operating wide differentials between levels, had produced a flood of merely academically qualified persons with none of the technical skills actually in scarce supply. Technical training institutes were consequently an obvious and attractive alternative to further secondary schools for harambee organizers.

In these circumstances the institutes of technology, first of all, provide platforms for those bidding for local leadership. In this they are like previous harambee, only bigger. Secondly, they are, as we shall argue later, an interesting manifestation of the further spread of bureaucratic influence - for the first time we have harambee projects initiated by civil servants rather than by politicians. Thirdly, they may represent a new stage in the tribalization of Kenyan politics, a process which has already gone a long way. Fourthly, the fact of dependency sets the constraints within which the institutes will operate, affecting both what they can do and what their impact on the economy and society can be.

The plans, or rather aspirations, of the institutes vary a great deal from the near-university-level courses of Ramogi Institute of Advanced Technology, near Kisumu, to the village-polytechnic or technical-school curricula of Embu Karurumo, Maa (Kajiado) and Samoei (Nandi). These aspirations have already been scaled down significantly and will undoubtedly be scaled down further in the face of fund-raising difficulties, increases in cost estimates and the growing realization of the difficulties involved in setting up and running high-level technical training institutions. Although the entrance requirement of secondary form IV schooling, stipulated by most, is likely to remain, it would not 
be surprising to find the majority of institutes, starting with courses at skilled rather than semi-professional level. The difficulties that the institutes are likely to meet in fund-raising can be illustrated by a comparison of their combined initial fund-raising targets of Shs 200 million (about $\$ 28$ million) with actual cash contributions for all self-help purposes during the six-year period 1967-72, estimated at Shs 124 million ( $\$ 17$ million), a shortfall of 38 per cent. Indeed it begins to appear that the crucial determinant of the institutes' achievement and impact will be the amount of foreign capital aid that they are able to attract. We estimate, on plausible assumptions, that for all the institutes to reach their fund-raising targets by 1977 over Shs 100 million ( $\$ 14$ million) in foreign aid will be needed. Since aid on such a scale is unlikely, the immediate impact of these projects may be rather smaller than had originally been thought. Nevertheless, sooner or later the institutes will be making demands on the Kenyan economy, particularly for staff and recurrent finance, which will be difficult to meet. The prospect of taking over responsibility from their recurrent expenditure must be particularly worrying for the Kenyan Treasury.

A further constraint is the existing system of technical training. In general, the sort of training that is going on in the formal sector, whether on or off the job, is the sort of training which is required by foreign-dominated industry using imported technology and imported standards. Moreover, the increasing formalization of apprentice-training, with its levies and stringent requirements, is likely to be at the expense of the cheap and efficient (albeit exploitative) training which is going on in the informal sector. We carried out a survey of existing training institutions and of their plans for expansion. This highlighted the problem of the shortage of staff, which was particularly acute at sub-professional level, and showed the way in which unit cost tended to rise with the level of training. It also identified certain categories for which there appear to be adequate facilities (in relation to the demands of the existing political/economic structure $^{3}$ ) and others for which they are inadequate. Almost 34,000 technicians and craftsmen, our survey suggested, are likely to emerge from existing training institutions and on-the-job training in 1972-77 -

3 But not, of course, necessarily in relation to the demands of any alternative or 'ideal' structure. 
representing an annual average rate of increase in the stock of such skilled workers of between 5 and 7 per cent. Perhaps the most interesting finding here is that, although many of the institutes have based their plans on the supposed shortage of engineering technicians, in fact this group is reasonably well supplied with training facilities. Indeed, this might be a category in which accelerated Kenyanization will become necessary to avoid a surplus. In other words, the graduates of the harambee institutes may find themselves in sharp competition with those of the official institutes; and the government may find itself with an excess of technically trained people.

Some have suggested that overproduction, particularly of technicians, would impart a more technical orientation to society and open new areas of innovation. Kenya is certainly starting from a relatively low level of indigenous technical skill and consciousness. Traditional skills, such as smithing, and apprenticeship systems existed in pre-colonial times. But during the colonial period Indian craftsmen and technicians were imported, so that it was not necessary to encourage Africans to acquire industrial skills. Also, the racially segregated education and training system effectively prevented those Africans who wanted to acquire higher-level skills from doing so. Meanwhile the structure of demand changed in such a way that the traditional skills and apprenticeships largely fell out of use. In this context the campaign for institutes of technology is at least encouraging in the sense that it is raising questions about the role of technology in development, the means of adapting technology to local needs, the relative importance to society of technically and academically educated people and the types of economic strategy that encourage innovation.

However, we are far from optimistic about the chances of the institutes of technology technicalizing African society through their output of trained technicians. For one thing, we are sceptical about the possibility of training institutions in a dependent economy doing much more, in their curricula and syllabuses, than reflect the demands of the existing political/economic structure. In this case, these are not for craftsmen and technicians skilled in improvising solutions to a wide range of technical problems. Instead they are for people trained to service the products sold by or the machines used in a particular firm and to replace rather than to repair, whenever difficulty arises. If there were a 
change in that structure, such that, for instance, an indigenous capital goods industry were set up, the consumer goods industry shifted from producing standardized import-reproducing goods for the high-income market, to devising new ways of meeting the needs of those with low incomes, and income differentials were drastically reduced, then the situation would be different. At the same time exciting training possibilities for the institutes and exciting ways in which their trainees could be utilized would be opened up. As it is, however, it seems likely that the institutes will be assigned the role, both by the multinational corporations and by the political petty bourgeoisie, of producing 'service' technicians and craftsmen for the existing structure. This will also be the role which the institutes' trainees will be looking for, given the structure of rewards in the economy. Overproduction of trainees who have been exposed to curricula and syllabuses shaped by the acceptance of such a role could be a serious matter, since they are unlikely to be sufficiently adaptable and innovative for lucrative self-employment in their trade. Frustration rather than technicalization will be the probable outcome.

We turn now to the institutes' indirect effects. Insofar as they transfer resources from immediate to less immediate productive use they will slow down the rate of economic growth in their early years. More important is their possible disequalizing effect on income distribution. Although conspicuous donations are being extracted from the political petty bourgeoisie, most local contributors are non-asomi ${ }^{4}$, particularly small farmers. If the institutes persist in their intention to offer courses mainly for Form IV leavers and set their fees at Shs 3,000 (\$420) a year or more (as has Kiambu) ${ }^{5}$, it could be said with only slight exaggeration that money was raised from the poor to provide channels to jobs for those children of the rich who failed to get in to university. Besides accentuating in equalities between classes within regions there is also a

4 i.e. the bulk of the African population, outside the political petty bourgeoisie and not assimilated during colonial times in to the role of 'good colonials'. See Mutiso, 'Cleavage and the Organizational Base of Politics in Kenya: a theoretical framework', Journal of East African Research and Development, vol. 3 (1), 1973.

5 The ILO Kenya Report estimated that over 76 per cent of households have an annual income of less than Shs 2,400 , over 87 per cent less than Shs 4,000 and over 96 per cent less than Shs1 2,000. 
danger of accentuating inequalities between regions. Different regions have different fund-raising capacities, with Central and Rift Valley Provinces at a distinct advantage. It is no accident that Kiambu and Muranga, two of the richest districts, have so far been able to raise the largest amounts locally. Moreover, since the richest region is also the most influential politically, it seems likely that foreign aid will reinforce rather than counteract the disequalizing effect. (Kiambu has so far been the only institute to at tract large-scale foreign aid). Of course, politics is not static and one could make various predictions of 'success rates' for institutes depending on the foreign aid implications of future political scenarios. Most of the feasible ones, however, involve continuing regional inequality. Moreover the return to their areas of origin of the bureaucrats, while having the obvious healthy effect of forcing accountability on politicians, raises the danger of strengthening majimboistic (regional) feeling. Regular meetings of ethnic elite members are now being held and, whatever the immediate aims, the process of interaction inevitably creates local solidarity, at the cost of a larger divisiveness.

Does the founding of the institutes of technology mark the end of the explosion in the demand for academic education? This looks unlikely. For one thing, if they prove initially successful in placing their trainees in jobs, they will probably be faced with an excess of applicants and may react to this by raising entry qualifications. This has already happened to training institutions such as the National Youth Service, which were originally intended for primary school leavers. Thus the scramble for academic qualifications as means of entry could be heightened rather than discouraged by the institutes. Moreover, while the enthusiasm for technical training is new and, in a sense, revolutionary from the view of the history of education, the curricula and syllabuses, as has already been emphasized, are unlikely to be innovative. Pressure from both the Ministry of Education and employers will be for 'recognized' qualifications (i.e. trade tests and City and Guilds). It would be a brave principal who resisted such pressure, when simultaneously faced with his immediate need to demonstrate the employability of his products.

The institutes seem to fit in well with the characterization of self-help as 'pre-emptive development'. That is, they stake a powerful claim to 
future government funds, rather than offer substitute and additional resources. Indeed, the way in which they were chosen as projects suggests that their initiators were looking for something not only likely to be taken over by the government and to attract overseas aid but also unlikely to be independently initiated by the government. Like previous harambee projects, the institutes are vehicles for personal political ambitions. Unlike most previous harambee projects, however, each of the institutes is too large and covers too wide an area to become the personal property of a single leader. Quarrels over leadership partly explain the multiplication of institutes in some areas, particularly Western Province, and the dead-lock within institutes in others, particularly Ukamba and Meru.

Moreover, as we have already emphasized, in an important respect the institutes-of-technology campaign represents something entirely new in Kenyan politics - the return to their areas of ethnic origin of members of the bureaucratic stratum of the political petty bourgeoisie. In describing this group as 'bureaucrats' we are not, of course, intending to imply that we think they are non-political; indeed, part of our argument is that they are playing a highly political role. The point is that this group had not tended to get much involved in harambee before. Previous projects tended to be on a smaller scale, covering an area no bigger than a division, and were dominated by members of parliament who used them as a means of interacting with their constituents. The importance of bureaucrats in the institutesof-technology campaigns can be illustrated by reference to their predominance among members of critical committees and holders of national office and, most convincingly, by an analysis of the way in which the institutes were initiated and the major decisions made. In at least eleven cases the initiating role of bureaucrats seems to have been crucial.

Perhaps the most obvious contrast between the institutes and previous harambee is one of sheer size. The magnitude of the amounts to be raised has been one of the reasons for the involvement of the provincial administration in fund-raising, the compulsion exerted on contributors, the tapping of sources other than kinsmen and the need to look outside the country for a large proportion of funds. Lonrho, Unilever, Shell BP and the Aga Khan Group are some of the largest contributors and some 
leading politicians (including the President) have made conspicuous contributions across ethnic boundaries. Only one institute has been successful in attracting large-scale foreign aid, however - Kiambu which has received a grant of some Shs 6.7 million ( $\$ 0.9$ million) from the Dutch government via a church organization (thus circumventing a rule that private projects are not allowed to receive aid direct from foreign governments).

A final, distinctive feature of the institutes, which will already have become apparent, is the way in which they are a focus for the interests of a large number of influential groups. They have, for instance, been legitimized at the highest levels of government, with the President taking an active part in various ways and many ministers and assistant ministers being involved in their own area's institutes. The government, through the provincial administration, is also intimately involved in the process of raising funds. Multi national corporations have reason to co-operate with enthusiasm. They are hirers of skilled labour, suppliers of materials and equipment and, not insignificant, buyers of political insurance. The lower income-groups who form the majority of contributors have supported the idea. However, they are beginning to ask questions about who will benefit, and collection methods are arousing intense bitterness. In the words of a Murang'a trader, 'We are not going to sit back and sing 'hallelujah' when our children are expelled from schools for non-payment of school fees, and when we cannot take them to hospitals when they fall sick, all in the name of harambee spirit'.

Few have spoken against the harambee institutes. The most coherent opposition has come from the professional central planners, largely the expatriates. They set out the contradiction between official government planning for technical training, and the threatened distortions by officials acting in quasi private capacities. Their criticisms, particularly strong in the early days of the campaign, made sense in the context of central planning, but ignored the political economy of the situation. The disappointing response of the foreign aid donors may indicate suppressed criticism of the deviation from central planning. Equally it may stem from the strongly political nature of the movement and the dangers inherent for bilateral aid agencies. Primary school leavers, who know that the institutes are not for them, take a jaundiced view, but, despite their numbers, are not politically influential. 
As part of our research we made a special study of the Kiambu Institute of Science and Technology which began operating in July 1973. This highlighted the way in which Kiambu bureaucrats have manipulated their positions to gain access to resources for KIST. Moreover, Kiambu has set a precedent for access to foreign funds and project planning expertise, which other institutes will be trying to follow - to the possible embarrassment of government. The need for a professional project evaluation and the early appointment of a project director is an obvious lesson of KIST's experience. Another lesson is that the problem of cost - both escalating capital cost and the impossibility of raising enough by fees to cover recurrent expenditure -- is likely to be the major preoccupation of all institutes. By May 1973 the total estimated capital cost of the project had risen to Shs 19.8 million ( $\$ 2.8$ million) more than double the Shs 8.5 million ( $\$ 1.2$ million) originally estimated. Moreover, the fees set at Shs 3,000 per year, although they meet only half the running costs, are too high for all except those from wealthy families. The final lesson of our Kiambu case-study is that the pressures of the existing political economy largely determine what it is possible for an institute to do, even though a wary attitude towards the proposals of foreign companies can be shown. ${ }^{6}$ Thus KIST is offering a two-year building course, with three streams (carpentry, masonry and plumbing). It is oriented towards eventual self-employment, and involves practical work during the course inside and outside KIST as well as training in the techniques of management. However, the course will also fit in with the existing formal system by taking entrants direct from secondary technical school (Form IV) and by offering a preliminary year to those who have been to a non-technical secondary school to take them up to East African Certificate of Education (technical) standard. Moreover, while the main qualifications to be offered will be a KIST certificate, trainees will be able to take government trade tests. And while KIST has admirably insisted that all applicants should take aptitude tests, it has stopped short of opening access to these tests to those with less than four years of secondary schooling. In short, the institute has implicitly recognized (1) that it must demonstrate the employability of its products within the existing structure and that a wage-earning job is what most trainees will be

6 Kiambu turned down an offer from one company of a grant to finance courses in the use of repair of that company's equipment. 
looking for and (2) that unemployed secondary-schooled entrants are available in large numbers and are regarded by the elite as one of Kenya's most serious problems.

With the institutes of technology we have obviously come a long way from the original concept of 'self-help' projects. In effect, the full weight of individual members of the government and of the provincial administration has been thrown behind the raising of funds to build institutions the recurrent financing of which will at some time become the responsibility of the government. What exactly they will eventually look like remains to be seen. But even at this early stage they have aroused unprecedented interest in Kenya and have become the catalyst of a wide-ranging discussion involving politics, economics and technology as well as education and training. Further, they have reinforced the lesson of the original harambee schools: namely, the difficulties of centralized educational planning in a situation where schooling is indispensable to advancement - and therefore intensely pursued - and where self-help projects are used by politicians and 'non-politicians' alike as a means of attracting local political support. 